\title{
Apontamentos para um Estudo sobre a Gênese da pesquisa em Educação Matemática no Brasil: a Especialização em Modelagem Matemática em Guarapuava/PR
}

\author{
Notes for a Study on the Genesis of Research in Mathematics \\ Education in Brazil: Specialization in Mathematical Modelling in \\ Guarapuava / PR
}

\author{
Leoni Malinoski Fillos* \\ ORCID iD 0000-0002-5110-0234 \\ Antonio Vicente Marafioti Garnica** \\ ORCID iD 0000-0003-0750-8483
}

Há uma série de fatores - muitos além daqueles que traremos à cena neste texto - que operam como ingredientes a partir dos quais vai se delineando o que hoje conhecemos pela rubrica “pesquisa em Educação Matemática no Brasil”. Falar de uma gênese, portanto, não é detectar um ponto, uma circunstância, uma pessoa ou um grupo a partir dos quais algo é gerado, se desenvolve e se consolida, dado que essas são situações dificilmente detectáveis fora de um entremeado de ações, instituições, acasos, gerências, ingerências, intenções, fracassos e sucessos que não se pode descrever de forma linear, nem se compreender se não de um modo, digamos, rizomático, sempre considerando a vinculação visceral entre pessoas,

\footnotetext{
* Doutora em Educação Matemática pela Universidade Estadual Paulista "Júlio de Mesquita Filho" (Unesp, campus Rio Claro). Docente da Universidade Estadual do Centro Oeste (UNICENTRO), Irati, Paraná, Brasil. Endereço para correspondência: Rua Ladislau Griczinski, 429, Centro, Irati, Paraná, Brasil, CEP: 84502-244. Email: leonimfillos@hotmail.com.

** Doutor em Educação Matemática pela Universidade Estadual Paulista "Júlio de Mesquita Filho" (Unesp, campus Rio Claro). Livre-docente pelo Departamento de Matemática da Universidade Estadual Paulista "Júlio de Mesquita Filho" (Unesp), Bauru, São Paulo, Brasil. Endereço para correspondência: Avenida Nações Unidas, 11-35/1101, Centro, Bauru, São Paulo, CEP: 17010-130. E-mail: vicente.garnica@unesp.br.
} 
instituições, circunstâncias e eventos. Se esses nossos apontamentos tentam contribuir para estudos sobre a gênese da pesquisa em Educação Matemática no Brasil, é nesses termos que o fazemos, do que se torna tão conveniente quanto necessário situar, como essas nossas considerações foram engendradas.

A pesquisa da qual se originaram esses apontamentos (FILLOS, 2019) teve como intenção inicial analisar a dinâmica de idealização e desenvolvimento dos primeiros cursos de Especialização em Modelagem Matemática, ocorridos em Guarapuava, Paraná, nos idos dos anos 80 , de modo a compreender alguns dos determinantes políticos e sociais para a sua realização no contexto da formação continuada dos professores daquela década. Estudamos o movimento de criação e desenvolvimento da Fundação Faculdade de Filosofia, Ciências e Letras de Guarapuava, os embates políticos, desafios e contradições até a sua transformação em Universidade, à luz de depoimentos ${ }^{1}$ tanto dos professores e administradores da instituição, quanto de professores que propuseram e/ou desenvolveram os cursos de Especialização em Modelagem Matemática, além de documentos e outras fontes que nos permitiram uma aproximação a esse contexto histórico. Portanto, arbitramos a década de 1980 e os cursos de Especialização em Modelagem Matemática de Guarapuava como início dessa nossa pesquisa. As conexões entre esses cursos e outros vários ingredientes que, à época, de algum modo, convergiram para criar e levar à consolidação do campo de pesquisa em Educação Matemática no Brasil são o ponto focal dos apontamentos que apresentamos aqui.

\section{Uma instituição no interior do Paraná}

O cenário desse nosso estudo tem como uma de suas principais marcas a Fundação Faculdade Estadual de Filosofia, Ciências e Letras de Guarapuava (Fafig), entidade de Ensino Superior criada em julho de 1968, pela lei 5.804 do Estado do Paraná, no âmbito de uma política desenvolvimentista do governo do estado e de um projeto de nação contraditório e conservador, já que passávamos por um momento político em que o Estado brasileiro estava organizado em bases autoritárias, que se fundara por meio de um golpe de estado e que definira como classe política dirigente um grupo de militares. O país estava inserido em um regime ditatorial apoiado pelo capital internacional que visava, de forma incisiva, a implantar políticas de modernização e abrir espaço no mercado interno para as multinacionais.

\footnotetext{
${ }^{1}$ Foram entrevistados: Rodney Carlos Bassanezi, Eduardo Sebastiani Ferreira, Regina Luzia Corio de Buriasco, Maria Salett Biembengut, Dionísio Burak, Sidnei Ragazzi, Nelson Zagorski, Sílvio de A. Pregnolatto, João Frederico da C. A. Meyer, Paulo Roberto Mendes Guimarães, Vitor Hugo Zanette e Irene Raquel Garcia. Foram também mobilizadas entrevistas disponibilizadas integralmente em outros estudos.
} 
No Ensino Superior, a contraditoriedade se revelava de maneira explícita nas ações e regulamentações da época. Por um lado, o governo federal exercia total controle ideológico e político do ensino, com vistas a eliminar a crítica social e política, a partir de violenta intervenção nas universidades, repressão, demissões, exílio e total desarticulação de movimentos estudantis. Por outro lado, apostava em uma política de ampliação da oferta de vagas e de expansão das Instituições de Ensino Superior (IES) em todo país, em resposta à pressão exercida pela classe média, que exigia mais vagas em faculdades e universidades para acabar com o problema dos excedentes ${ }^{2}$. O discurso nacionalista de modernização, frente ao desenvolvimento da economia e das tecnologias e da necessidade de mão de obra qualificada, contribuía para a elaboração de projetos de ampliação da rede de instituições de nível superior $^{3}$. Ironicamente, é no primeiro decênio do regime militar que ocorre a grande expansão desse nível de ensino no Brasil que a ditadura tão fortemente combateria, caracterizando-o como um nicho de libertários comunistas, algo não muito distante da tentativa de desqualificação que se tem, hoje, como as insinuações de balbúrdia do Ensino Superior brasileiro.

No Paraná, a estratégia adotada pelo governo de Paulo Pimentel ${ }^{4}$ - forte aliado do governo militar - ao assumir o estado em 1965, foi sedimentar a política e a economia no modelo que ficou conhecido como "ideologia do desenvolvimento integrado", um conjunto de ações governamentais que buscava integrar regiões, áreas, diversos setores de atividade e diferentes camadas populacionais ao processo de expansão do capitalismo monopolista no Estado, incluindo a incorporação de políticas voltadas para o setor social (educação, saúde, saneamento, habitação) e de formação de recursos humanos qualificados. Dentre outras ações, fazia parte dessa estratégia de desenvolvimento a proposta de expansão e interiorização do Ensino Superior no Paraná como fator de consolidação e desenvolvimento das cidades interioranas e ampliação das oportunidades de formação e das demandas de serviço de educação e saúde (SHEEN, 2000).

\footnotetext{
2 "Excedentes" é o termo usado para os alunos que obtinham pontuação suficiente nos vestibulares eliminatórios, mas não conseguiam ingressar no ensino superior por falta de vagas. Para resolver este problema, na década de 1970, o governo passou a adotar o mecanismo do vestibular classificatório.

${ }^{3} \mathrm{~A}$ conjuntura política brasileira da época abriu caminho para a aprovação de uma série de regulamentações sem o aval da sociedade civil, dentre as quais a lei 5.540, de 28 de novembro de 1968, que fixou "normas de organização e funcionamento do ensino superior e sua articulação com a escola média". Conhecida por Reforma Universitária, a referida lei foi aprovada após um estudo detalhado da universidade brasileira, realizado por uma comissão de especialistas, composta de americanos e brasileiros, nos termos do convênio MEC-USAID. A lei $n^{\circ}$ 5.540 esteve norteada por dois princípios básicos: o controle político das universidades públicas e a formação de mão de obra para economia

${ }^{4}$ Paulo Cruz Pimentel foi governador do Paraná de janeiro de 1966 a março de 1971, pelo Partido Trabalhista Nacional (PTN).
} 
De fato, durante o governo de Paulo Pimentel, a expansão e interiorização ganha força e, nesse contexto, são instituídas, pela lei $\mathrm{n}^{\circ}$ 6.034, de 06 de novembro de 1969, as três primeiras universidades no interior do $\operatorname{estado}^{5}$, a partir da reunião de estabelecimentos de Ensino Superior da região de abrangência: a Universidade Estadual de Ponta Grossa (UEPG), a Universidade Estadual de Londrina (UEL) e a Universidade Estadual de Maringá (UEM). Também são criadas diversas instituições isoladas de ensino ${ }^{6}$, dentre as quais a Faculdade de Filosofia, Ciências e Letras de Guarapuava, no centro-oeste do Paraná.

Para Fonseca (1992), um fator que contribuiu para a criação das instituições isoladas, que exigiam investimentos menores, foi o processo de interiorização. Reforçado pelo conceito de que a educação induz ao desenvolvimento econômico, o provincialismo das cidades do interior encontrava na instalação de uma escola superior a oportunidade do município conquistar o prestígio enfraquecido pelo desenvolvimento das áreas metropolitanas.

A Fafig, portanto, foi criada em um momento político favorável para a expansão das IES e sob o discurso da modernização e do desenvolvimento, no contexto paradoxal dos "Anos de Chumbo" e do "Milagre Econômico Brasileiro" interior do Paraná: esteve articulado a um projeto de nação que vinha sendo delineado pelas elites econômicas e políticas desde o início do regime militar. Não podemos desconsiderar, entretanto, que esse processo foi resultante também de um jogo de forças e muita pressão local frente ao governo de Estado.

De acordo com Marcondes (1985), desde o início da década de 1950 já ocorriam manifestações na sociedade guarapuavana em prol de uma instituição de Ensino Superior. Como a economia do município era predominantemente voltada à agropecuária, o objetivo inicial era criar uma Escola de Agronomia e Veterinária, cujo projeto, porém, apresentado na Assembleia Legislativa do Estado em 1953, foi vetado com a justificativa de alto custo para os cofres públicos e de escassez de corpo docente qualificado.

Passou-se então a discutir a possibilidade de criação de uma Faculdade de Filosofia, tendo em vista que a quase totalidade do corpo docente das escolas de Ensino Médio no município era leiga. Em meados da década de 1960, Guarapuava contava com uma população

\footnotetext{
5 Até essa época, o Paraná contava somente com duas universidades, localizadas na capital, Curitiba: a Universidade Federal do Paraná, criada em 1912 (apesar de não haver consenso dessa data, detalhes em Wachowicz (2006)), e a Pontifícia Universidade Católica, de caráter privado, criada em 1959.

${ }^{6}$ Como instituições isoladas entendem-se as faculdades independentes de um órgão central de administração, podendo ser privadas ou públicas (municipal, estadual ou federal).

7 “Anos de Chumbo" é a designação do período mais repressivo da ditadura militar no Brasil. Teve início em 1968, com a edição do Ato Institucional 5, e durou até o final do governo Médici, em março de 1974.

8 "Milagre econômico brasileiro" é a denominação dada à época de aceleração do crescimento do PIB (Produto Interno Bruto) e da massiva industrialização ocorrida durante o regime militar, entre 1969 e 1973.
} 
próxima a 100 mil habitantes e carecia de profissionais capacitados para as diversas funções que o município requisitava. $\mathrm{O}$ aumento populacional gerou a necessidade de escolarização e formação de professores para atender a demanda.

Mesmo diante da necessidade flagrante de professores, foram muitos embates políticos, forte pressão da imprensa local e regional e intensas mobilizações frente ao governo do Estado até a criação da faculdade. Merece destaque a importante atuação da Congregação dos Padres Salvatorianos ${ }^{9}$ - especialmente dos padres Francisco Contini e Egídio Ragassi que se uniu à comunidade política local para elaboração do projeto de criação da faculdade e, posteriormente, cedeu o imóvel para a instalação da instituição. A pressão exercida por vereadores, prefeitos e deputados da região foi também determinante para a consolidação do ato de criação da faculdade. No ano de 1967, o deputado estadual Moacyr Julio Silvestre, posteriormente prefeito de Guarapuava, apresentou na Assembleia Estadual do Paraná o projeto de lei 37/67 que, no ano seguinte, foi aprovado pelo então governador do Paraná.

Após a assinatura do decreto de criação da Fafig, a comunidade guarapuavana teve que esperar ainda um ano e meio para que a faculdade fosse instalada, devido ao trâmite burocrático legal exigido pelas regulamentações. Em janeiro de 1970, o Presidente da República, General Emílio Garrastazu Médici ${ }^{10}$, autorizava, enfim, o funcionamento da Fafig, marcando o início do Ensino Superior em Guarapuava ${ }^{11}$.

A Faculdade começou a funcionar como uma autarquia e, adaptando-se à Lei Estadual $\mathrm{n}^{\mathrm{o}}$ 6034, de 06 de novembro de $1969^{12}$, foi transformada em uma Fundação de Direito Público, passando a denominar-se Fundação Faculdade Estadual de Filosofia, Ciências e Letras de Guarapuava, sendo o primeiro diretor o Pe. Francisco Contini, da Congregação dos Salvatorianos.

\section{Os primeiros anos da Fafig}

As atividades acadêmicas na Fafig foram iniciadas em março de 1970 com quatro cursos de licenciatura: Letras, História, Geografia e Matemática. O curso de Pedagogia, que inicialmente fazia parte do projeto, foi considerado "desnecessário", porque a profissão de

\footnotetext{
${ }^{9}$ Sociedade do Divino Salvador ou Congregação dos Salvatorianos é um instituto religioso apostólico, de direito pontifício, fundado em Roma em 1881.

${ }^{10}$ Presidente da República de 30 de outubro de 1969 a 15 de março de 1974.

${ }^{11}$ Autorização dada pelo decreto $\mathrm{n}^{\circ} 66.083$, de 16 de janeiro de 1970.

12 A Lei 6.034, de 06 de novembro de 1969, criava oficialmente as Universidades de Ponta Grossa, Maringá e Londrina e instituía, pelos incisos $1^{\circ}$ e $2^{\circ}$, que os estabelecimentos de ensino seriam organizados como "fundação de direito público" e que a denominação oficial da instituição deveria ser antecedida da designação "Fundação".
} 
pedagogo ainda não era regulamentada e não se via a necessidade do professor do Ensino Primário possuir uma formação superior, sendo suficiente a formação no Ensino Normal ${ }^{13}$ (MARCONDES, 1985). Os alunos interessados na área de Pedagogia tiveram que esperar ainda alguns anos para que o curso fosse autorizado ${ }^{14}$.

O processo de reconhecimento dos primeiros cursos junto ao Ministério de Educação e Cultura (MEC) teve início dois anos depois de efetivo funcionamento da Faculdade. Quando as primeiras turmas estavam se formando, em 1973, o Conselho Federal de Educação (CFE) já havia se pronunciado favoravelmente ao reconhecimento dos quatro cursos.

Os alunos aprovados no primeiro vestibular, em fevereiro de 1970, eram, em sua maioria, professores que já lecionavam em escolas da região. Este cenário era muito comum na época em todo o Brasil, uma vez que, devido à escassez de professores formados, muitas pessoas que possuíam apenas Ensino Médio, às vezes incompleto, atuavam como docentes em escolas de nível médio. Com o tempo, esses professores procuravam regularizar a situação profissional, prestando exames de suficiência ${ }^{15}$, frequentando programas emergenciais ${ }^{16}$ ou se matriculando em cursos de licenciatura (MARTINS-SALANDIM, 2012; MORAIS, 2017).

Apesar da Fafig ser uma instituição pública estadual, os alunos pagavam uma mensalidade, assim como em outras IES recém criadas no Paraná, embora fossem mais baratas que as instituições privadas. O ensino só era de fato gratuito nas instituições federais. Não havia ainda lei federal alguma que obrigasse o Estado a arcar com o financiamento integral do Ensino Superior. Esse sistema de pagamento, que contribuía para a elitização do ensino, iria perdurar por quase duas décadas na Fafig. A gratuidade do Ensino Superior no Paraná só foi garantida após a mobilização das faculdades e universidades estaduais, marcada pela presença estudantil e pela União Paranaense de Estudantes (UPE), que exerceram forte $\operatorname{pressão}^{17}$.

Quanto aos primeiros professores que lecionaram na Fafig, quase todos eram procedentes de Ponta Grossa e recém-formados pela recente universidade instalada naquela cidade. A maioria, bastante jovem, viu-se desafiada a lecionar para turmas de professores,

${ }^{13}$ A Lei de Diretrizes e Bases no 4024/61, art. 52, regulamentava que "o ensino normal tem por fim a formação de professores, orientadores, supervisores e administradores escolares destinados ao ensino primário, e o desenvolvimento dos conhecimentos técnicos relativos à educação da infância".

${ }^{14} \mathrm{O}$ curso de Pedagogia foi autorizado a funcionar, na Fafig, em outubro de 1976, e suas primeiras turmas iniciaram as aulas em março do ano seguinte.

${ }^{15}$ Exames prestados por candidatos à docência que não tinham formação inicial adequada, segundo a legislação vigente. Os aprovados recebiam um registro com validade para a região em que poderiam exercer o magistério.

${ }^{16}$ Programas implantados com o objetivo de fornecer formação para professores já atuantes e sem a habilitação necessária. Dentre os programas emergenciais, destaca-se a Campanha de Aperfeiçoamento e Difusão do Ensino Secundário (CADES), que vigorou no país no período de 1953 ao início da década de 1970.

${ }^{17}$ A gratuidade do Ensino Superior no Paraná foi oficializada pela Lei no 8675, de 21 de dezembro de 1987. 
muitos deles com anos de experiência profissional no ensino regular. Muitos docentes passaram a enfrentar dupla ou tripla jornada de trabalho em Guarapuava, pois além de atuarem na Faculdade, trabalhavam em escolas da região. Alguns deles assumiram funções administrativas na instituição. Assim que as primeiras turmas concluíram os cursos na Faculdade, alguns alunos recém-formados passaram a integrar o corpo docente da mesma instituição, um movimento natural a quase todos os cursos superiores brasileiros. Nesse contexto, quando a Fafig começou a funcionar, 90\% ou quase 100\% dos professores eram apenas graduados, nos relata Garcia em Fillos (2019), apesar da legislação da época já relacionar a ascensão na carreira docente à obtenção de títulos de Mestrado e Doutorado. Cabia aos cursos stricto sensu, além do desenvolvimento da pesquisa, formar quadros para o magistério superior e criar as mais altas formas de cultura universitária (MARAFON, 2001).

\section{Especialização e Pós-Graduação}

A Pós-Graduação na legislação brasileira é definida a partir de duas modalidades: lato sensu, que corresponde aos cursos de Especialização e de Aperfeiçoamento, e stricto sensu, que abrange os cursos de Mestrado e de Doutorado. Historicamente, ambas têm se constituído em um importante instrumento de qualificação de profissionais das mais distintas áreas do saber, porém, enquanto o stricto sensu tem merecido atenção e incentivos tanto das políticas de governo quanto da pesquisa acadêmica, o lato sensu nem sempre teve sua natureza e seus objetivos bem explicitados nas regulamentações. Grande parte dos pareceres e resoluções limita-se a conceituar essa modalidade de ensino realçando somente seu aspecto práticoprofissional. Ao longo dos anos, ela tem se desenvolvido "sem identidade conceitual, desvinculada do sistema nacional de pós-graduação e, em muitos casos, exógena à política de graduação e ao próprio eixo estrutural da política de pós-graduação" (FONSECA, 2004, p. 176).

A expressão "pós-graduação" aparece pela primeira vez na legislação em 1946, em decreto que firma o Estatuto da Universidade do Brasil. É utilizada para definir os cursos universitários destinados aos diplomados, com a finalidade de formação sistemática de especialização profissional. Posteriormente, a Lei de Diretrizes e Bases da Educação Nacional (LDB) $n^{\circ} 4.024 / 61$ deu o primeiro passo na regulamentação dos cursos de pós-graduação ao distinguir três categorias de Ensino Superior: (a) graduação, (b) pós-graduação e (c) especialização, aperfeiçoamento e extensão (BRASIL, 1961). 
Ao enquadrar os cursos de especialização e aperfeiçoamento em uma categoria distinta da pós-graduação, sem uma definição clara, a lei $n^{\circ} 4.024$ deu abertura para que instituições de Ensino Superior utilizassem de maneira equivocada esses termos. Por isso, em 1965, o Conselho Federal de Educação, com a colaboração do professor Newton Sucupira, emitiu o parecer 977 que regulamentou a pós-graduação e deliberou seus objetivos nos seguintes termos:

1) formar professorado competente que possa atender à expansão quantitativa do nosso ensino superior, garantindo, ao mesmo tempo, a elevação dos atuais níveis de qualidade;

2) estimular o desenvolvimento da pesquisa científica por meio da preparação adequada de pesquisadores;

3) assegurar o treinamento eficaz de técnicos e trabalhadores, intelectuais do mais alto padrão para fazer face ao desenvolvimento nacional em todos os setores (BRASIL, 1965).

Este parecer, seguindo modelo norte-americano, definiu os dois tipos de pósgraduação no Brasil: stricto sensu, com objetivo de natureza acadêmica, de pesquisa e de cultura; e lato sensu, com finalidade eminentemente prática, voltado à formação de profissionais para o mercado de trabalho. Tal dispositivo representa um marco importante da pós-graduação stricto sensu, uma vez que estabeleceu princípios gerais que orientam sua organização e funcionamento. Já os cursos lato sensu permaneceram sem uma regulamentação específica que deliberasse quais eram seus objetivos e com que finalidade os certificados poderiam ser utilizados, carecendo, portanto, de conceituação e delimitação precisa de sua função.

Desse modo, se por um lado o Parecer Sucupira representa um texto fundador da pósgraduação sistemática no Brasil, por outro, pode ser visto como a referência que provocaria uma divisão radical entre os cursos de "pós-graduação sistemática" daqueles de "pósgraduação não sistemática" (FONSECA, 2004; ABRÃO, 2007).

Em 1968, o relatório elaborado pelo Grupo de Trabalho encarregado de estudar a reforma da Universidade Brasileira (GTRU) definiu a pós-graduação como a cúpula de estudos em que deveria se desenvolver a pesquisa científica e se formar os quadros do magistério superior e, portanto, como "condição básica para transformar a Universidade brasileira em centro criador de ciências, de cultura e de novas técnicas" (BRASIL, 1968, p. 39). Da mesma forma que o Parecer Sucupira, o relatório do GTRU insistia na urgência de uma política nacional que centralizasse esforços na institucionalização de programas de Mestrado e Doutorado, estimulando iniciativas para formação do professor do Ensino Superior. A lei 5.540/68, também chamada de Lei da Reforma Universitária, amparada por 
outros decretos, passou a reforçar a necessidade de títulos de pós-graduação (Mestrado ou Doutorado) para a contratação e promoção de professores universitários.

Em que pesem os avanços desses dispositivos legais, indicando a necessidade de estudos pós-graduados aos docentes do Ensino Superior, em cidades interioranas do Brasil a realidade era outra. Em Guarapuava, por exemplo, em que um enorme contingente de professores das escolas regulares, no início da década de 1970, sequer tinha graduação, não era possível compor o quadro de docentes da Faculdade recém instalada no município com professores mestres ou doutores. Alguns professores da Faculdade de Guarapuava, nesse tempo, se matricularam em programas de Mestrado, mas as dificuldades eram enormes porque tinham que viajar toda semana para assistir aula, já que era impossível afastá-los de suas atividades acadêmicas. Ainda assim, resultado das políticas que vinham sendo desenvolvidas pelo MEC para o Ensino Superior, os professores das IES passaram a não se sentir seguros e a perceber a necessidade de prosseguir os estudos em cursos de pósgraduação. Alunos que concluíam a graduação e aspiravam à docência no Ensino Superior também passaram a buscar programas de pós-graduação. Diante das dificuldades e da escassez de programas stricto sensu, procuravam fazer pelo menos uma especialização.

A validade dos certificados de aperfeiçoamento e especialização como instrumento de qualificação na carreira do magistério superior foi legalizada pelo Conselho Federal de Educação com a aprovação da resolução n. ${ }^{\circ}$ 14/77, considerada a primeira regulamentação específica para a pós-graduação lato sensu. Dentre as determinações dessa resolução destacam-se algumas, como a que os cursos de aperfeiçoamento e especialização fossem ministrados por instituições de Ensino Superior que oferecessem curso de graduação reconhecido ou curso de pós-graduação credenciado e a definição da carga horária mínima de 360 horas, realizada no máximo em dois anos, sendo pelo menos 72 horas dedicadas a matérias complementares e de formação didático-pedagógica (BRASIL, 1977).

A resolução CFE n 14/1977 vigorou por seis anos e foi revogada com a publicação da resolução CFE $n^{\circ}$ 12/1983 que ratificava a vinculação dos cursos lato sensu à carreira docente para o magistério superior. Dentre as inovações, a nova resolução previa a inclusão de conteúdos de iniciação à pesquisa na carga horária dos cursos e determinava que, pelo menos, 60 horas fossem destinadas às disciplinas de formação didático-pedagógica, requisitos que indicavam uma preocupação com a qualificação dos egressos que (teoricamente) poderiam atuar no Ensino Superior (BRASIL, 1983).

Até 1988 não havia uma diferenciação na legislação entre os cursos de especialização e os de aperfeiçoamento. Ambos estavam inseridos indistintamente na pós-graduação lato 
sensu. Foi o parecer CFE no 69/1988 que apresentou uma caracterização dos cursos em função da carga horária mínima, ficando em 180 horas para cursos de aperfeiçoamento e 360 horas para especialização. A decisão veio em resposta às regulamentações que estabeleciam percentuais de acréscimos salariais para os professores federais de acordo com o curso: 10\% para especialização e 5\% para aperfeiçoamento. Como a especialização implicava o dobro de aumento no salário, ficou instituído que ela deveria ter, no mínimo, o dobro de duração em relação aos de aperfeiçoamento (BOLDRIN, 2007).

Em decorrência da expansão das IES no Brasil e da escassez de vagas em cursos stricto sensu, na década de 1970 e início dos anos 80, os cursos de pós-graduação lato sensu, portanto, se constituíram como medida estratégica mais adequada para prover o atendimento da crescente demanda por professores para o magistério superior. A nova conjuntura políticoeducacional, por sua vez, produziu outra perspectiva: uma formação de professores com iniciação à pesquisa científica, cujo princípio se estendeu a todos os níveis de ensino (OLIVEIRA, 2012).

\section{Os cursos de especialização da Fafig}

Diante das dificuldades dos docentes da Fafig para frequentar um curso de Mestrado, a saída encontrada pelos dirigentes, nos primeiros anos de funcionamento da instituição, foi investir em cursos de pós-graduação lato sensu. Esses cursos, além de possibilitar a formação de professores para o Ensino Superior e para o Ensino Básico de Guarapuava, permitiriam à instituição angariar mais recursos, uma vez que a verba destinada pelo estado à Faculdade era insuficiente e que os cursos seriam pagos pelos alunos.

Nesse contexto, a pós-graduação na Fafig teve início em 1975, na modalidade de especialização, sendo ofertados primeiramente os seguintes cursos: Metodologia do Ensino Superior; Geografia Econômica, Urbana e Agrária; Cálculo Avançado; História SócioEconômica; Literatura Portuguesa e Brasileira e Língua Portuguesa I. Tais cursos tiveram início em novembro de 1975 e finalizaram em agosto de 1976, com um total de 375 horas/aula, sendo 4/5 dessa carga horária destinada às disciplinas específicas. Além disso, todos os cursos contavam com duas disciplinas complementares comuns: Estudo dos Problemas Brasileiros, com 15 horas/aulas - ministrada por dois professores, sendo um deles coronel do exército; e Metodologia e Técnicas de Pesquisa, com 60 horas/aula, que evidencia a preocupação com a formação de pesquisadores, um dos objetivos da pós-graduação, de acordo com o Parecer Sucupira. 
A maior parte dos docentes do curso de Especialização em Cálculo Avançado vinha do IMECC $^{18}$, da Universidade Estadual de Campinas (Unicamp), e entre eles estava o professor Rodney Carlos Bassanezzi. Conforme se observa nas fontes consultadas, o professor Rodney ministrou três disciplinas nessa Especialização: Cálculo Avançado, Equações Diferenciais e Estatística e Probabilidade. Outros dois professores do IMECC, Mauro Bianchini e Irineu Salles Batarce, ministraram, respectivamente, Variáveis Complexas e Álgebra Linear.

Posteriormente, já na década de 1980, houve um crescimento acentuado da pósgraduação em âmbito nacional, tanto stricto como lato sensu. A Fafig, nesse contexto, promoveu a reorganização da especialização, impulsionando a criação de novos cursos. Assim, em 1981, os cursos são retomados sob uma nova estrutura: a carga horária é distribuída em três fases e as aulas passaram a se concentrar em períodos de férias escolares. Além disso, a instituição passou a oferecer alojamento em suas próprias dependências para alunos que residiam fora de Guarapuava, o que barateava os custos de estadia na cidade, algo marcante porque inédito.

Essa estrutura, que aos poucos começou a ser conhecida nas instituições de ensino, passou a atrair um contingente muito grande de alunos, transformando a Fafig em um centro de capacitação em nível de especialização. A Instituição passou a receber pessoas não apenas da região de Guarapuava, mas de todo Brasil, uma vez que a opção por realizar os cursos no período de férias representava um atrativo, pois contribuía para a vinda de docentes de outras instituições, que não precisavam deixar suas aulas regulares na graduação.

A finalidade dessas Especializações era "permitir ao graduado aprofundamento teórico e prático dos conhecimentos adquiridos na graduação e melhor habilitação para o desempenho da profissão em nível de Ensino Superior” (FAFIG, 1981). Os objetivos dos cursos, de acordo com o Regimento da Especialização da Fafig, foram traçados inicialmente nos seguintes termos:

I - especializar professores para o magistério superior;

II - oportunizar especialização aos graduados sem possibilidades de se afastarem de suas atividades, por tempo relativamente longo, para cursar pósgraduação (Mestrado ou Doutorado);

III - desenvolver e aperfeiçoar a pesquisa científica, nas áreas de especificação;

IV - contribuir para o atendimento das exigências do ensino, da sociedade, dos objetivos da Reforma do Ensino Superior preconizada na Lei 5540, da Lei 5692/71 e das necessidades decorrentes de sua implantação;

\footnotetext{
${ }^{18}$ Instituto de Matemática, Estatística e Computação Científica da Universidade de Campinas/SP.
} 


\begin{abstract}
V - cooperar com os esforços do Poder Público e de outros setores, para acelerar a preparação qualitativa de recursos humanos, exigida pelo desenvolvimento do país (FAFIG, 1981).
\end{abstract}

Nessa perspectiva, os cursos de especialização da Fafig eram entendidos como espaço de formação do professor do Ensino Superior, mas também como oportunidade de prosseguimento dos estudos da graduação e como meio de contribuir no atendimento da legislação educacional vigente dos diferentes níveis de ensino. Até o final da década de 1980, a instituição promoveu diversos cursos de especialização, em distintas áreas do conhecimento ${ }^{19}$.

Os depoentes que colaboraram com nossa pesquisa ressaltam que, para trabalhar nesses cursos, a Faculdade priorizava contratar docentes de universidades renomadas, como a Unicamp, a Unesp, a USP, a Universidade Federal de São Carlos e a Universidade Federal do Paraná, o que representava um chamariz adicional quando da divulgação dos cursos. O Regimento dos Cursos estabelecia que o corpo docente deveria ser formado por professores que possuíssem, no mínimo, o título de mestre, obtido em instituição credenciada (FAFIG, 1981).

Com o tempo, os cursos foram transformados em um programa e a Faculdade passou a receber apoio financeiro da Capes. Uma parte da verba era destinada às despesas parciais do curso, como pagamento de professores, outra parte para bolsas de estudo.

\title{
5 Um curso de especialização: pretexto para a proposição de uma ideia
}

É no contexto dos anos finais do regime militar que os cursos de especialização da Fafig são reestruturados. $\mathrm{Na}$ área de Matemática, de fundamental importância foi a atuação de um grupo de professores do IMECC, da Universidade Estadual de Campinas. Esses professores, aproveitando o espaço de autonomia metodológica que a faculdade proporcionava, apostaram em uma ideia ainda pouco difundida no Brasil à época e que se tornaria um campo de pesquisa e de promoção de conhecimentos que se multiplicaria proficuamente no país: a Modelagem Matemática ${ }^{20}$.

\footnotetext{
19 Vale destacar a oferta de cursos na década de 1980 relacionados à Educação Especial, em convênio com a Universidade Federal de São Carlos, que indicam um olhar atento dos docentes e gestores da Faculdade para questões relacionadas à inclusão educacional, na época ainda pouco usual. Precisamente, a especialização que teve início em 1984, realizada na área de Deficiência Mental, é considerada a primeira pós-graduação lato sensu desenvolvida em Educação Especial no Paraná, área que posteriormente ganhou força em todo o estado (ALMEIDA, 2004).

${ }^{20}$ Utilizaremos, vez ou outra, somente o termo "Modelagem" para designar Modelagem Matemática, de modo a evitar repetições.
} 
De fato, a Modelagem Matemática foi apresentada, discutida e desenvolvida em um curso de pós-graduação voltado à formação de professores, pela primeira vez, em Guarapuava, quando foi ofertada a "Especialização em Ensino de Matemática", de janeiro de 1983 a janeiro de 1984, sob a coordenação de Rodney Carlos Bassanezi. Ele foi convidado pela equipe dirigente da Fafig a organizar o curso, tendo autonomia para estruturar as disciplinas, as ementas e o cronograma, bem como para compor o corpo docente da especialização. Ele já havia trabalhado em outros cursos de especialização na Fafig, em Cálculo Avançado e em Estatística, sendo, portanto, já conhecido da equipe gestora.

Em sua entrevista para este estudo, o professor Rodney relata que planejou a especialização como um espaço para fortalecer os conceitos trabalhados na graduação, e organizou as ementas com conteúdos da área de Matemática, como Análise, Geometria, Topologia e Equações Diferenciais. Contudo, quando as inscrições começaram a chegar, ele percebeu que o grupo de alunos era bastante heterogêneo: alguns ainda na graduação ${ }^{21}$, enquanto outros eram professores com muitos anos de experiência. Isso levou Bassanezi, como coordenador, a alterar instintivamente, segundo ele mesmo afirma, a estrutura do curso, sugerindo que, em grupos, os alunos investigassem a Matemática presente no cotidiano a partir de um tema escolhido por eles. Propôs, então, que os participantes fizessem visitas a empresas de Guarapuava ou a algum local em que se desenvolvia um ramo específico de atividade econômica e coletassem dados que os induzissem a formular problemas matemáticos relacionados ao tema escolhido. Desse modo, questões da realidade impulsionaram a realização do curso, ou seja, todas as disciplinas passaram a trabalhar na busca de soluções dos problemas criados pelos alunos.

A imprevisibilidade de organização e desenvolvimento desse curso representa um exemplo de que o campo educacional de formação docente agrega dimensões em que os arranjos, na prática, se dão, muitas vezes, em movimento ou em trajetória, à revelia das programações. O espaço institucional de formação docente é caracteristicamente regulado por regras, procedimentos e condutas científicas que privilegiam a padronização de um saber fazer, porém é também, fundamentalmente, um espaço de resistência, não controlado, em que podem se instituir desafios e novos caminhos, haja vista as subjetividades dos sujeitos envolvidos.

A Especialização, em resumo, mostrou-se inovadora e desafiadora para a época, uma proposta liberta de regras firmemente impostas, tanto para professores como para os alunos

${ }^{21}$ Eram alunos graduados em Ciências - Licenciatura Curta, e cursavam a Complementação em Matemática. Por já possuírem um título de graduação, puderam matricular-se em curso de pós-graduação. 
que, acostumados a aulas tradicionais - com explicações do conteúdo no quadro, listas de exercícios, correção de atividades e uma avaliação final na forma de prova escrita -, vislumbraram uma nova forma de se fazer Matemática, tendo como princípio inúmeras situações-problema. Eles nunca tinham sequer ouvido a palavra “Modelagem”. Na época, essa metodologia era praticamente desconhecida no Brasil e poucos movimentos em direção a ela podiam ser observados, inclusive no exterior.

De acordo com Biembengut (2009), a expressão "Modelagem Matemática" já era encontrada no início do século XX na literatura internacional de algumas áreas, como Engenharia e Ciências Econômicas, porém, no campo da Educação, ideias relacionadas a modelos no ensino de Matemática aparecem somente na segunda metade do século XX, em publicações nos Estados Unidos ${ }^{22}$. Tais ideias emergem ao mesmo tempo em que o ensino de Ciências procurava enfatizar práticas envolvendo situações experimentais e, analogamente, matemáticos americanos, preocupados com o ensino, buscavam apoio no método de Resolução de Problemas, com Polya, e na Modelagem Matemática com profissionais da Matemática Aplicada (FIORENTINI, 1996).

Embora a Matemática Aplicada, no início do século XX, já tivesse se constituído como uma área autônoma de conhecimento, a escola, meio século depois, ainda privilegiava o movimento internalista da Matemática, ou seja, "a produção de matemática a partir de problemas oriundos da própria matemática já sistematizada”. As raras aplicações reduziam-se a problemas clássicos de final de capítulo, que muitas vezes se distanciavam da realidade e eram pouco significativos para a vida do aluno (FIORENTINI, 1996, p. 3).

Nesse contexto, na década de 1960, as práticas tradicionalmente desenvolvidas no ensino de Matemática passaram a ser questionadas mais fortemente e debates sobre aplicações no ensino começaram a ocorrer no cenário internacional, especialmente no chamado movimento "utilitarista" 23 , que impulsionou a formação de grupos de pesquisadores sobre o tema, como o de Hans Freudenthall, na Holanda ${ }^{24}$, e o de Bernhelm Booss e Mogens Niss, na Dinamarca. Na Europa, eventos sobre o ensino de Matemática e situações da realidade começam a ser realizados a partir de 1968, contribuindo para a formação, em 1983, do Grupo

\footnotetext{
${ }^{22}$ Evidências sobre a utilização das ideias de modelos matemáticos são encontradas em uma coleção de textos publicados entre 1958 e 1965; em trabalhos realizados pelo School Mathematics Study Group (SMSG) entre os anos de 1966 a 1970 e em publicações de Henry Pollack no 69 anuário da National Society for the Study of Education e no New Trends in Mathematics Teaching IV, no qual o autor apresenta um panorama sobre as aplicações matemáticas no ensino e detalha o processo de construção de modelos (BIEMBENGUT, 2009).

${ }^{23}$ Definido como aplicação prática dos conhecimentos matemáticos para a ciência e a sociedade.

${ }^{24}$ IOWO - Institut On twikkeling Wiskundeonderwijs (Instituto para o Desenvolvimento da Educação Matemática), fundado em 1971, atualmente Freudenthal Institute (FI).
} 
Internacional de Modelagem Matemática e Aplicações - ICTMA ${ }^{25}$, que agrega interessados em Modelagem Matemática na perspectiva da Educação Matemática e organiza, bianualmente, evento voltado a discutir o panorama internacional sobre o tema: a International Conference on Teaching Mathematical Modelling and Applications (ICTMA ${ }^{26}$ ).

Remetendo-nos ao cenário brasileiro, podemos afirmar que o ano de 1983, considerado um marco no exterior devido à constituição do ICTMA, representa também um marco das atividades com Modelagem Matemática no Brasil tendo em vista a realização do curso de Especialização em Guarapuava. Esse marco (brasileiro) indica que movimentos referentes às ideias de modelos matemáticos ou ensino com ênfase na Matemática "da realidade" já eram desenvolvidas ou pensadas no país.

De fato, no início da década de 1970, estudos ligados à área da Matemática Aplicada já eram desenvolvidos na Unicamp, especialmente com alunos da iniciação científica. Contudo, é a partir de 1974 que um grupo de professores se engaja mais firmemente na utilização de aplicações da Matemática envolvendo fenômenos do mundo real, em disciplinas da graduação e na orientação de trabalhos de iniciação científica e de pós-graduação. Esses professores, anos depois, dariam origem a uma área de investigação que se tornaria conhecida como "Biomatemática", na qual os fenômenos biológicos, sobretudo problemas relativos ao meio ambiente ou à saúde, passaram a ser investigados pelo método da Modelagem Matemática (FIORENTINI, 1996).

Dentre os primeiros pesquisadores a investir em práticas de ensino e de pesquisa na Modelagem no Brasil destaca-se Rodney Carlos Bassanezi. Um de seus alunos de iniciação científica, João Frederico da Costa Azevedo Meyer, mais conhecido por Joni, refere-se a Rodney como um professor entusiasta, inquieto com o ensino tradicional e incomodado com questões relativas à aplicabilidade e à utilidade da Matemática. Ele fora seu orientador de iniciação científica em 1969. Devido às influências de Bassanezi, João Frederico, segundo ele próprio, tornou-se um aluno ativo, curioso e passou a se sentir atraído por problemas envolvendo aplicações na Matemática. Assim, logo que concluiu a graduação, ingressou como professor no IMECC e iniciou o Mestrado na Unicamp, tendo como orientador o professor Ubiratan D'Ambrosio, que havia recém chegado do EUA.

\footnotetext{
${ }^{25}$ International Community of Teachers of Modelling and Application. Recentemente, o ICTMA afiliou-se ao ICMI (International Comissionon Mathematics Instruction) passando sua sigla a significar "The International Study Group for Mathematical Modelling and Applications".

26 A primeira ICTMA ocorreu em 1983, na Exeter University, no Reino Unido, tendo dela participado 125 pessoas de 23 países. Ocorreram no evento duas palestras plenárias e mais 39 em sessões paralelas. A maioria das apresentações abordava a Modelagem na Educação Superior; somente 5 eram relativas à Escola Básica (BIEMBENGUT, 2015).
} 
Joni nos relata, em entrevista, que Ubiratan D'Ambrosio, logo que chegou ao Brasil, assumiu o cargo de diretor do IMECC, mostrando-se muito atento às produções em termos de Educação Matemática em nível internacional, sempre com uma postura questionadora frente à Matemática e seu ensino, até mesmo ao que se praticava no próprio Instituto. Em suas aulas no curso de Licenciatura em Matemática e em programas de pós-graduação, utilizava modelos matemáticos como estratégia de ensino e estimulava outros docentes a realizarem projetos dessa natureza. Assim, Ubiratan foi um grande incentivador para que os professores do IMECC desenvolvessem um olhar crítico para a Matemática, com uma concepção de ensino voltada à realidade sociocultural. Seus estudos teórico-pedagógicos seriam decisivos para a consolidação/divulgação da Modelagem Matemática como método de ensino.

Apesar dos estudos pós-graduados de D’Ambrosio estarem voltados à Matemática Pura, paulatinamente ele utilizou sua atuação de matemático como forma de fortalecer o que tinha a dizer à Educação. Ou seja, suas teorizações progressivamente permitiram o estabelecimento de relações entre a Matemática e a Educação Matemática e se alinharam em defesa das questões culturais como ponto central do processo pedagógico. Suas publicações e pesquisas, ao longo dos anos, estenderam-se também ao campo da Filosofia, da História da Educação e dos estudos transdisciplinares, e passou a perceber na Modelagem uma forma especial de resolução de problemas, que permitia relacionar a Matemática ao contexto sóciocultural e político do aluno.

Uma das políticas adotadas por Ubiratan, logo que chegou à Unicamp, foi ampliar o quadro docente do IMECC, possibilitando a vinda de pesquisadores com Doutorado de outras instituições brasileiras e também do exterior, principalmente dos EUA. Tal princípio, além de possibilitar a estruturação da pós-graduação em Matemática no Instituto, permitiu que vários professores mestres pudessem iniciar seus doutorados na própria Unicamp, dentre eles Rodney Bassanezi, o primeiro a defender uma tese sob orientação de um professor do IMECC, no caso, Ubiratan D'Ambrosio, em $1977^{27}$.

D’Ambrosio exerceu o cargo de diretor do IMECC de 1972 a 198028. Suas contribuições, nesse período, transcenderam as fronteiras do Brasil, especialmente quando propôs o mestrado "Ensino de Ciências e Matemática", em convênio com Programa de

\footnotetext{
${ }^{27} \mathrm{Na}$ entrevista disponível em Vianna (2000), Bassanezi explica que duas teses foram defendidas no Programa antes deles, porém sob orientação de professores da Universidade de São Paulo. Considerando a orientação de um professor do IMECC, sua tese foi a primeira a ser defendida.

${ }^{28}$ Posteriormente exerceu o cargo de Pró-Reitor de Desenvolvimento Universitário, de 1982 a 1990.
} 
Expansão e Melhoria do Ensino (PREMEN) ${ }^{29}$ e a Organização dos Estados Americanos (OEA). Foram 4 turmas, em média com 32 alunos cada uma, com ingresso, respectivamente, nos anos de 1975, 1976, 1977 e 1978.

Outro projeto realizado no IMECC, sob a coordenação de Ubiratan D’Ambrosio, foi a produção de materiais de apoio didático, voltados ao ensino de $1^{\circ}$ grau, sobre vários temas matemáticos. Esse projeto, desenvolvido também com o apoio do PREMEN, evidencia a preocupação de Ubiratan e de outros professores com questões relativas à escola básica. Docentes do IMECC, de outras IES e de escolas de Ensino Básico participaram desse projeto, dentre os quais, Regina Buriasco, que integrou o grupo para elaboração do volume do $3^{\circ}$ e $4^{\circ}$ anos do material chamado Iniciação à Matemática ${ }^{30}$. Outro grupo, segundo a professora Regina, produziu um material intitulado Geometria Experimental.

Percebe-se, assim, que Ubiratan D’Ambrosio impôs um novo perfil ao IMECC, que até então direcionava o ensino e a pesquisa estritamente à Matemática Pura e Aplicada. A partir desse período, na segunda metade da década de 1970, consolida-se no Instituto um grupo de matemáticos que volta seu olhar para assuntos também relacionados ao ensino e à aprendizagem da Matemática desde a escolarização básica.

Dentre esses matemáticos, Rodney Bassanezzi, nessa nova atmosfera instaurada no IMECC, volta seu interesse à Modelagem Matemática, tornando-se, posteriormente, como já mencionado, uma referência singular no impulso dessa área no Brasil.

Bassanezi, em sua entrevista, diz que um dos motivadores para que ele definitivamente voltasse sua atenção à Modelagem Matemática foi Aristides Barreto ${ }^{31}$, um professor da PUC do Rio se Janeiro que, por convite de Ubiratan D'Ambrosio, foi à Unicamp ministrar um curso sobre as atividades que vinha desenvolvendo. Eduardo Sebastiani Ferreira também participou do curso ministrado pelo professor Aristides no IMECC.

De acordo com Bassanezi, a decisão de realizar alguma experiência com Modelagem Matemática com professores veio após a oferta de um curso no IMECC, em 1981, para aproximadamente 30 professores de Cálculo Diferencial e Integral (CDI), de diversas Instituições de Educação Superior da região Sul do Brasil. O curso teve duração de uma semana e Bassanezi, como coordenador do curso, fez a seguinte proposta aos participantes:

\footnotetext{
${ }^{29}$ Programa criado pelo Decreto $\mathrm{n}^{\mathrm{o}} 70.067$, de 26 de janeiro de 1972, com o objetivo principal de aperfeiçoar o sistema de ensino de primeiro e segundo graus no Brasil. Este programa absorveu o Programa de Expansão e Melhoria do Ensino Médio - PREMEM - aprovado pelo Decreto nº 63.914, de 26 de dezembro de 1968.

${ }^{30}$ Publicação do material anos depois em Gazzetta et al (1986).

31 Aristides Camargo Barreto orientou as duas primeiras dissertações em Modelagem Matemática da PósGraduação da PUC-RJ, em 1976 e 1979. Tais dissertações são consideradas as primeiras na área da Modelagem no Brasil.
} 
eles deveriam se reunir por duas horas e apresentar um problema que envolvesse CDI, diferente de problemas que já existiam em livros da área. Duas horas depois, para sua surpresa, mas também decepção, a maioria dos problemas propostos era igual aos que se apresentavam nos livros. Essa experiência, segundo ele, o levou a perceber a necessidade de se propor mudanças no processo de ensino e aprendizagem e que era preciso efetivar "uma Educação Matemática mais criativa do que simplesmente resolver problemas. Era preciso pensar uma Matemática mais voltada à realidade, inventar, pegar coisas e transformar em Matemática". Foi, portanto, um momento crucial para que ele voltasse sua atenção para a Modelagem Matemática, porque, em seu entendimento, "o potencial da Modelagem é criar problemas, mais do que resolver problemas" ${ }^{\prime 2}$.

Assim, nesse curso para professores de CDI, aliando ensino e pesquisa, Bassanezi percebeu que o método de produção de conhecimentos em Matemática Aplicada auxiliava de forma eficaz no enfrentamento das dificuldades que os professores apresentavam em relação às ideias essenciais do Cálculo e, principalmente, às aplicações em situações-problema de fenômenos da realidade. Um ano depois surgiu a oportunidade de trabalhar em Guarapuava, na Fafig. Diante de um grupo de professores novatos ou com muitos anos de experiência, Bassanezi percebeu a circunstância adequada para propor algo diferente também para professores de outros níveis de ensino.

\section{0 primeiro curso}

Era janeiro de 1983 e em Guarapuava, no Paraná, se iniciava o curso de “Especialização em Ensino de Matemática". Tendo optado por reelaborar o curso de modo a motivar práticas interdisciplinares, atreladas à realidade específica da região, e valorizar o conhecimento matemático dos professores cursistas, Bassanezzi, com a autonomia que lhe fora concedida pela equipe gestora da Fafig, convidou docentes vinculados ao IMECC ou que já haviam desenvolvido algum projeto naquele Instituto e organizou o curso em três fases, como a direção da Fafig havia solicitado.

O programa do curso, inicialmente elaborado com módulos de Cálculo Diferencial e Integral, Análise, Topologia, Álgebra Linear etc., após as mudanças, passou a ter, na Fase I, as disciplinas Etno Matemática e o ensino (ministrada por Eduardo Sebastiani Ferreira, da Unicamp), Módulo de Aprendizagem I e II (ministrados, respectivamente, por Regina

\footnotetext{
${ }^{32}$ Excertos da narrativa de Rodney Carlos Bassanezi em Fillos (2019).
} 
Buriasco, da UEL, e Marineusa Gazzeta, da Unicamp), Estudo de Problemas Brasileiros I (ministrado por Gilberto Saciloto, Carlos de Bortoli e Paulo Jorge Rihes, todos da Fafig); na Fase II, Modelos Matemáticos I e II (ministrados respectivamente por Silvio Pregnolatto e Rodney Bassanezi, ambos da Unicamp); na Fase III, Modelos Matemáticos III (ministrado por Bassanezi), Metodologia Científica e Aplicada (ministrada por Luiz Roberto Dante ${ }^{33}$, da Unesp) e Estudos dos Problemas Brasileiros II (disciplina para a qual não está registrado o docente responsável $)^{34}$.

Observa-se na documentação referente ao programa das disciplinas desse curso a ausência de bibliografia sugerida para a disciplina Etno Matemática e o Ensino, em cujo espaço indica-se "não há bibliografia por ser assunto recente de pesquisa", enquanto que para as disciplinas referentes aos Módulos de Aprendizagem (I e II) consta a expressão "livros didáticos de $1^{\circ}$ e $2^{\circ}$ graus". Para as disciplinas referentes aos Modelos Matemáticos (I, II e III), a bibliografia remete a livros didáticos de $2^{\circ}$ e $3^{\circ}$ graus, além de uma apostila organizada por Bassanezi e intitulada Modelos Matemáticos para o ensino de Cálculo. Não há registros da bibliografia utilizada na disciplina de Metodologia Científica e Aplicada.

Nota-se, assim, que o foco das ementas e da bibliografia eram os conteúdos matemáticos, especialmente de $2^{\circ}$ e $3^{\circ}$ graus, não havendo uma proposta de discussão mais aprofundada sobre tópicos relacionados à Educação. As disciplinas Estudos de Problemas Brasileiros (I e II), comuns a todos os cursos de especialização da Fafig naquela época, foram ministradas na modalidade "palestra"; a primeira, por três conferencistas (um médico, um

\footnotetext{
${ }^{33}$ Consta na documentação de planejamento do curso que a disciplina Metodologia Científica Aplicada seria ministrada a priori pelo professor da Fafig, Giocondo Fagundes, porém no histórico escolar disponibilizado pelo professor Vitor Hugo Zanette, que foi aluno dessa turma, consta o nome do professor Luiz Roberto Dante como docente responsável pela disciplina.

${ }^{34}$ Seguem as ementas de cada uma dessas disciplinas:

Etno Matemática e o Ensino: Embasamento sobre etno matemática e técnicas de pesquisa de campo. Reconhecimento das situações reais da comunidade, fábrica, hospitais, restaurantes... Levantamento de dados quantitativos e qualitativos. Sistematização dos dados coletados. A escola como agente de integração comunitária. Módulo de Aprendizagem I: Formulação lógica da pesquisa de campo. Matemática elementar aplicada a problemas reais. Estudo analítico para o $1^{\circ}$ grau. Modelagem de problemas concretos. Módulo de Aprendizagem II: Correlação entre o mundo real e a matemática de $2^{\circ}$ e $3^{\circ}$ graus. Pesquisa de laboratório construção de modelos. Modelos concretos para situações reais. Grupos de trabalho. Modelos Matemáticos I: Sequências e progressões, arranjos, permutações, combinações, probabilidades; geometria plana e espacial; trigonometria, logaritmos e exponencial; matrizes e sistemas de equações. Modelos Matemáticos II: Funções (polinomiais, logarítmicas, exponenciais, trigonométricas); limites (números reais, uso de calculadora), derivada - taxa relacionada, crescimento e decrescimento de funções, máximos e mínimos, análise e gráfico de funções. Modelos Matemáticos III: Integrais - estudos de arcos, figuras planas; modelos físicos, uso de calculadora, regra Simpson; equações diferenciais ordinárias; sistemas especiais - com enfoques; modelos matemáticos aplicados à Biologia, Epidemologia, Economia, Física, Quimica, Ecologia. Metodologia Científica Aplicada: Método científico; a metodologia como ciência; normas para sublinhar textos. Estruturação de esquemas e resumos: ficha bibliográfica; referências bibliográficas; trabalhos científicos de campo experimentais; projeto de pesquisa; instrumentos de pesquisa; partes do trabalho científico; monografia. Estudo dos Problemas Brasileiros I: Educação e Saúde. Manifesto Ecológico. Aspectos da Matemática na Biologia.
} 
geógrafo e um biólogo), nos períodos de uma manhã e duas noites; a segunda, também por três conferencistas, porém não encontramos documentação que indique quem foram os palestrantes, nem os temas trabalhados.

Nos cursos, escolhidos os temas, os professores cursistas passaram à fase de pesquisa de campo, quando visitaram alguns espaços de Guarapuava e exploraram os ambientes, fazendo medições, entrevistando pessoas, coletando dados matemáticos. Essas atividades fizeram parte da disciplina "Etno Matemática e o Ensino", conduzida pelo professor Eduardo Sebastiani em conjunto com o professor Rodney, ambos atuando como orientadores dos grupos. Em sua narrativa, Regina Buriasco reitera a dinâmica adotada nesse primeiro curso, bem como em outros que ocorreram posteriormente na Fafig, afirmando que "já de início a turma era dividida em grupos e cada grupo escolhia um tema para trabalhar. Depois cada grupo ia buscar informações daquele tema para então desenvolver a Modelagem" 35 .

De posse dos dados, em sala de aula os participantes passaram a organizar as informações e a formular questões relacionadas ao tema escolhido para então modelar matematicamente. Tais questões evoluíam de um nível elementar a um nível mais complexo, podendo ser resolvidas a partir de conteúdos de diferentes graus de ensino. As questões formuladas pelos grupos constituíram-se em um norte para o desenvolvimento de todas as disciplinas do curso, ou seja, os professores passaram a trabalhar no sentido de auxiliar os grupos a obterem a solução das questões.

Conforme consta da documentação pesquisada, a turma da Especialização de 1983 era composta por 42 alunos, a maioria residente em Guarapuava ou municípios adjacentes. Havia alunos de outros municípios do Paraná, também de Santa Catarina e do Rio Grande do Sul.

Vale destacar que a metodologia de ensino utilizada em Guarapuava fora divulgada em uma publicação da Folha de São Paulo, de 04 de fevereiro de 1984. Na matéria, assinada por Laerte Ziggiatti, o jornalista ressalta que o método havia sido idealizado pelos professores Rodney Bassanezi e Eduardo Sebastiani, ambos da Unicamp, com o intuito de "contribuir para tornar a matemática mais acessível e atraente, possibilitando um entrosamento mais efetivo entre teoria e a realidade”. Sem se referir à Modelagem Matemática, Ziggiatti relata que o método, dirigido a professores de todos os níveis de ensino, buscava inverter o processo, ou seja, as questões matemáticas deveriam ser problematizadas a partir de fatos da realidade.

${ }^{35}$ Excerto da narrativa de Regina Buriasco em Fillos (2019). 
Com depoimentos de Bassanezi e Sebastini, a matéria da Folha de São Paulo descreve a experiência realizada em Guarapuava, na Fafig, esclarecendo que no desenvolvimento do curso não havia a preocupação por parte dos orientadores de ensinar Matemática, mas de adequar os conhecimentos individuais aos objetivos do método e aguçar a sensibilidade do aluno, desenvolvendo sua intuição e curiosidade. Tratava-se, assim, de algo mais do que uma nova metodologia de ensino, à medida que assumia um status de etnociência ao se aplicar os conhecimentos matemáticos provindos de um grupo cultural, como de trabalhadores da construção civil, da agricultura ou piscicultura.

Entendemos, a partir das fontes mobilizadas, que o primeiro curso de especialização para professores foi circunstancial e teve caráter de experimento, tendo em vista que, para Bassanezi, a turma supostamente não acompanharia os conteúdos anteriormente previstos de Matemática Pura. A proposta de ensino voltada à Modelagem parece ter agradado não somente aos alunos, mas principalmente aos professores que viram nessa abordagem um modo diferenciado de trabalhar os conteúdos, com uma participação mais efetiva dos alunos. A proposta da Modelagem, segundo eles, mostrou-se inovadora, especialmente quando considerando a disposição de alunos em grupos, realizando pesquisa de campo, sendo protagonistas do processo de ensino.

\section{Outros cursos: a difusão da proposta}

Diante dos resultados considerados positivos pelos envolvidos com a primeira experiência com Modelagem Matemática em um curso de especialização para professores e acreditando que aquele era um caminho apropriado para atender às expectativas de profissionais que buscavam "melhorar sua prática", o modelo proposto em Guarapuava serviu de base para a elaboração de muitos outros cursos de pós-graduação em distintas instituições do Brasil. Sob a coordenação de Bassanezi, e com outros professores do IMECC integrandose ao grupo, a proposta de ensino e aprendizagem com Modelagem Matemática foi se disseminando gradativamente e a metodologia foi conquistando adeptos em todas as regiões do país.

No final da década de 1980, início da década de 1990, outros cursos de especialização na área da Matemática, nos mesmos moldes dos da Fafig, já haviam sido realizados ou estavam em andamento em outras instituições brasileiras, como na Universidade Federal do Mato Grosso, em Cuiabá - MT, na Universidade Estadual de Ponta Grossa - PR, na Universidade Metodista de Piracicaba - SP, na Faculdade de Filosofia, Ciências e Letras de 
Cornélio Procópio - PR, na Universidade Regional do Noroeste do Estado do Rio Grande do Sul - Unijuí - RS e na Faculdade de Filosofia, Ciências e Letras de Palmas - PR. Carvalho (2010), em trabalho que busca destacar o pioneirismo de Rodney Carlos Bassanezi no desenvolvimento e divulgação da Modelagem Matemática no Brasil a partir do estudo de produções científicas formuladas sob sua orientação, apresenta uma relação dos cursos de especialização realizados sob a coordenação de Bassanezi ao longo das décadas de 1980, 1990 e 2000. São contabilizados por Carvalho vinte e dois cursos em instituições públicas e privadas.

As disciplinas dos cursos de especialização ministrados a partir de 1983 ficavam, em geral, sob a responsabilidade dos mesmos docentes do IMECC, havendo certa rotatividade entre eles. Com mais frequência trabalhavam os professores Bassanezi, Sebastiani, Marineusa Gazzetta, Sidnei Ragazzi, Paulo Guimarães, Sílvio Pregnolatto, João Frederico Meyer e Antonio Carlos Moretti. Outros professores participaram esporadicamente, como Laércio Vendite, José Luis Boldrini, Vera Figueiredo, Maria Salett Biembengut, Regina Buriasco e Dionísio Burak.

Os últimos cursos de especialização aconteceram, especificamente, segundo o professor Rodney, entre os anos de 2008 e 2010, na Universidade do ABC, em Santo André. Como nas propostas anteriores, as disciplinas concentraram-se nos meses de janeiro, fevereiro e julho (período de férias escolares), porém a dinâmica das aulas foi alterada: somente três professores ministraram as disciplinas ${ }^{36}$ e todo o trabalho foi realizado em conjunto por eles, desde o levantamento de temas à apresentação final dos grupos. Não houve uma participação intensa de professores do IMECC.

\section{A Educação Matemática na década de 1980}

As entrevistas realizadas para o desenvolvimento deste trabalho e as outras fontes mobilizadas na pesquisa nos permitem afirmar que a década de 1980 foi intensamente significativa para a Educação Matemática brasileira, enquanto área de conhecimento, estudos e pesquisa, tendo os cursos de especialização que investigamos um papel de destaque nessa conjuntura. O período de 1983 a 1990, especificamente, quando os primeiros cursos são realizados em Guarapuava, é caracterizado pela emergência de uma comunidade de

\footnotetext{
${ }^{36}$ Foram realizados dois cursos na Universidade Federal do ABC com a referida estrutura. As disciplinas ficaram sob a responsabilidade de Rodney Bassanezi e Paulo Roberto Guimarães, da Unicamp, e Geraldo Pompeu, da Universidade Federal de São Carlos.
} 
educadores matemáticos no Brasil, pela gradativa consolidação dessa comunidade e pela ampliação da região de inquérito da Educação Matemática, com o desenvolvimento de estudos e aplicações de novos métodos de ensino e com o surgimento de diversas linhas de pesquisa (FIORENTINI; LORENZATO, 2006).

Além da abertura do primeiro programa de pós-graduação stricto sensu em Educação Matemática e da criação de uma sociedade agregando educadores matemáticos de todo país, surgem, nesse tempo, novas linhas de estudo, como a Modelagem Matemática, a Etnomatemática, a Resolução de Problemas e a História da Matemática, confluindo pesquisadores e professores interessados em diversificar a prática investigativa e pedagógica. Dentre outros importantes focos que contribuíram para o surgimento e fortalecimento da Educação Matemática naquele tempo, podemos destacar o IMECC da Unicamp e a Unesp de Rio Claro, dois espaços com fortes ligações com os cursos de especialização que investigamos.

Como percebemos nas entrevistas realizadas para este estudo, é clara a contribuição de docentes do IMECC para a concretização de ações de ensino, pesquisa e extensão referentes à Modelagem Matemática, assim como é evidente a contribuição desses professores para a constituição da Educação Matemática no Brasil. Nesse Instituto, a partir da segunda metade da década de 1970, um grupo de matemáticos se articula em torno de propostas educacionais e volta seu interesse para questões referentes ao ensino e à aprendizagem da Matemática, possibilitando o desenvolvimento de atividades a partir de três eixos que consideramos basilares: o programa temporário de Mestrado, a elaboração de materiais didáticos e o movimento em torno da Modelagem Matemática e da Etnomatemática como propostas didático-pedagógicas.

O Mestrado em Ensino de Ciências e Matemática do IMECC-Unicamp, desenvolvido em convênio com MEC/PREMEN/OEA, vigorou de 1975 a 1984. Seu principal objetivo foi melhorar o ensino de Ciências e Matemática na América Latina, tendo como estratégia formar especialistas e lideranças nos vários países para promover cursos e programas, produzir materiais instrucionais, elaborar currículos, conduzir reformas etc. O programa teve, em toda sua vigência, 128 alunos, provenientes de diferentes estados brasileiros e de diferentes países da América Latina e do Caribe. Resultou na produção total de 72 dissertações de Mestrado, sendo os principais orientadores os professores Ubiratan D'Ambrosio (19 trabalhos), Sérgio Lorenzato (7 trabalhos) e Henry G. Wetzler (7 trabalhos) (D’AMBROSIO, 2014).

De acordo com Fiorentini (1994), os estudos desenvolvidos nesse programa pretenderam apresentar uma preocupação mais pragmática em relação à prática pedagógica e 
romper com o tratamento meramente quantitativo dos dados, dando início aos estudos de caráter intervencionista na prática. A Educação Matemática, portanto - mesmo que de forma tímida -, ganha ênfase nesse programa com estudos que priorizaram o desenvolvimento, a testagem e a validação de novos métodos e materiais instrucionais de ensino e de projetos de formação inicial e continuada do professor de Matemática (FIORENTINI, 1994).

A produção de materiais didáticos, também uma ação em convênio com o MEC/PREMEN, potencializou a formação de grupos de estudos no Instituto para discutir, analisar, elaborar e redigir textos de Geometria Experimental, Funções, Equações, Inequações etc., voltados às séries do $1^{\circ}$ grau e apropriados à realidade educacional brasileira ${ }^{37}$. Tal projeto, desenvolvido a partir de 1974 sob a supervisão de Ubiratan D'Ambrosio e a coordenação de Almerindo Marques Bastos, contribuiu para a promoção de vários cursos de formação continuada aos professores da escola básica. Alguns docentes que fizeram parte desses grupos de estudos trabalhavam em distintas IES ou em escolas de $1^{\circ}$ e $2^{\circ}$ graus, e se engajaram em outras atividades na Unicamp, tendo um olhar mais atento às questões que envolvem a Educação Matemática.

As ações que se traduziram no desenvolvimento da Modelagem Matemática, que inicialmente se concentraram em trabalhos científicos na área da Matemática Aplicada e em atividades de cursos regulares da Unicamp, foram impulsionadas com a realização de dezenas de cursos de especialização e de cursos de curta duração em diversas instituições de ensino no Brasil. Tais cursos permitiram a articulação de educadores em torno de uma ideia e a divulgação de um novo foco temático, visando conceber, testar e investigar outras maneiras de ensinar Matemática.

Da mesma forma, a Etnomatemática, que emergiu a partir de críticas ao ensino tradicional da Matemática e tendo como suporte trabalhos sobre cultura popular que vinham sendo realizados no IMECC, encontrou adeptos nesse Instituto que mobilizaram estratégias para promoção desse movimento, bem como para sua legitimação como um processo que envolve a produção, divulgação e circulação de distintas matemáticas, presentes em diferentes e múltiplos contextos culturais.

37 Segundo Almerindo Marques Bastos, entrevistado em Souza (1998), participaram do projeto: Marineusa Gazzetta, Afira Vianna Ripper (da área de História), Luiz Roberto Dante, Maria Aparecida Mendonça Jordão, Maria Célia Garbi, Maria José Piason Breglio e Renato Alvares Scanavini. Numa segunda fase participaram também Maria Luiza do Prado Zamarion, Gilberto Luis Moraes Selber, Divina Aparecida de Aquino, Clodoaldo Pereira Leite e Yeda Nice Gonçalves. Nosso estudo indica que Regina Buriasco também participou da segunda fase do projeto. 
Assim, tanto a Modelagem Matemática como a Etnomatemática encontraram solo fértil no IMECC para desenvolver e frutificar, tendo em vista o envolvimento de um grupo de professores com pensamentos convergentes a respeito de Educação, de ensino e de aprendizagem da Matemática. Apesar de não haver ainda uma comunidade nacional organizada e articulada em torno de questões de caráter educacional, científico, cultural, político e social sobre a Educação Matemática, no IMECC essa área do conhecimento ganha certa projeção com o desenvolvimento de pesquisas, formação de grupos de estudos, promoção de cursos e discussões em torno de tendências didáticas e investigativas.

Vale destacar a importante atuação nas ações envolvendo questões educacionais desenvolvidas no IMECC de alguém que optou por se tornar um matemático, mas que construiu, em paralelo e de forma gradativa, uma consistente formação para investir em questões da Educação de forma bastante incisiva: Ubiratan D'Ambrosio. Como diretor do IMECC, Ubiratan, mais que um arauto, foi um grande político, além de um importante agente na promoção da Educação Matemática, sem deixar de lado os interesses da Matemática Pura, área cuja pesquisa ele também contribuiu para alavancar, ao promover a vinda para a Unicamp de diversos matemáticos, já doutores, de distintas instituições do Brasil.

Mesmo com o dinamismo de D'Ambrosio, os envolvidos com as ações voltadas à Educação Matemática no IMECC não encontraram o devido apoio institucional nesse espaço, o que limitava a atuação individual dos docentes com relação à produção acadêmica. Eduardo Sebastiani relata na entrevista que nos concedeu ter experienciado resistências pautadas num discurso que questionava a natureza da pesquisa em um Departamento de Matemática. Segundo suas palavras,

Infelizmente, na Unicamp não tivemos suporte para o que estávamos fazendo. Não sei, mas nosso trabalho não foi muito bem aceito no nosso departamento. Achavam que a gente deveria estar fazendo pesquisa em Matemática Pura, que a gente não devia perder tempo com essas coisas. Não houve apoio nenhum (Eduardo Sebastiani Ferreira em FILLOS, 2019, p. 77).

Diante da dificuldade em trabalhar de modo direto com questões da Educação na Unicamp, no início da década de 1980, os professores Ubiratan D’Ambrosio, Rodney Bassanezi e Eduardo Sebastiani uniram-se a um grupo de docentes da Unesp de Rio Claro e de outras instituições e passaram a desenvolver pesquisas e atividades voltadas ao ensino e à aprendizagem da Matemática nessa instituição.

É importante destacar que a Unesp Rio Claro, já nesse tempo, mostrava-se na vanguarda com relação à prática e à pesquisa em Educação Matemática. Além da oferta de cursos de extensão universitária, de aperfeiçoamento e de especialização aos professores de 
Matemática em formação e em serviço, em 1980, a Secretaria da Educação do Estado de São Paulo assinou um convênio com o campus, com vistas à reestruturação de currículos e programas, formação continuada de docentes, organização de seminários e trabalhos com classes experimentais. Essas atividades, segundo Bicudo (2014), conduziram à reunião de professores e pesquisadores preocupados com questões da Matemática e seu ensino, oriundos de diferentes regiões do Brasil e de diversas instituições, dentre eles os já citados professores do IMECC. As discussões e ações desenvolvidas por esse grupo impulsionariam, alguns anos mais tarde, a criação de um programa de pós-graduação na área.

Com efeito, os debates políticos para a criação do referido programa se intensificaram a partir de 1982, principalmente com a vinda para a Unesp de Rio Claro da professora Maria Aparecida Viggiani Bicudo, uma das principais articuladoras do projeto. No ano de 1983, alguns alunos interessados no Programa passaram a fazer disciplinas com professores da instituição, pensando na iminência da abertura do Mestrado. Um desses alunos foi Dionísio Burak, que começou a trabalhar em um projeto com o professor Luiz Roberto Dante e a participar de um grupo de estudo com os professores Geraldo Perez, Mario Tourasse Teixeira e Eurides Alves de Oliveira.

O Mestrado em Educação Matemática da Unesp de Rio Claro foi o primeiro programa regular nessa área oferecido no Brasil. Teve início efetivamente em março 1984 como uma área de concentração do Mestrado em Matemática. Em 1987 deixou de ser apenas uma área de concentração passando a atuar em três linhas de pesquisa: 1) Fundamentos matemáticos e filosóficos da Educação Matemática; 2) Tendências atuais em Educação Matemática e; 3) Ensino e Aprendizagem da Matemática.

A primeira turma teve como alunos Maria Dolis, Dionísio Burak e Regina Luzia Corio de Buriasco, vindos de instituições paranaenses; José Geraldo Acioly Mendes da Silva, vinculado à Universidade Federal do Piauí; Marcelo de Carvalho Borba e Claudia Segadas Viana, ambos recém egressos de cursos de graduação cariocas; Luis Márcio Imenes e Marineusa Gazzetta, vinculados a instituições paulistas; e Eliane Scheid Gazire, então vinculada à Universidade Federal de Minas Gerais. Esses alunos foram selecionados entre aproximadamente cem candidatos, sendo que um dos critérios utilizados pela banca avaliadora foi "pegar pessoas diferenciadas, do Brasil todo, e com diferentes tipos de experiência" 38 .

\footnotetext{
${ }^{38}$ Excerto da entrevista de Maria Aparecida Viggiani Bicudo, realizada por Vicente Garnica, disponível na
} íntegra em Garnica e Bicudo (2018). 
Desses nove alunos selecionados, três foram orientados por Rodney Bassanezi e de alguma forma estiveram envolvidos com os cursos de Especialização em Modelagem de Guarapuava: Dionísio Burak, Marineusa Gazzetta e Maria Dolis. Outros dois alunos, embora não tenham desenvolvido seus mestrados tendo como foco a Modelagem, participaram ativamente da proposta de Guarapuava: Regina Buriasco ${ }^{39}$ ministrou disciplinas nos três cursos lá realizados; e Marcelo Borba ${ }^{40}$ foi monitor do curso de 1985-1986.

Desse modo, embora os primeiros trabalhos de Modelagem Matemática tenham emergido de Programas de Pós-Graduação da PUC-RJ e da Unicamp, é no Programa de PósGraduação em Educação Matemática (PPGEM) de Rio Claro, com a contribuição de professores do IMECC, que a Modelagem, enquanto tema de pesquisa e proposta de experiência prática, ganha forte impulso com estudos mais sistemáticos, traduzidos em dissertações de mestrado e, posteriormente, tornando-se foco de investigação de pesquisadores, como é o caso de Marcelo de Carvalho Borba, que fez da Modelagem uma de suas principais áreas de pesquisa. Das vinte e uma dissertações produzidas até o ano de 1990 no PPGEM, cinco delas tratam de aspectos teóricos e metodológicos da Modelagem Matemática $^{41}$. Numa tentativa de reflexão, sistematização e teorização dessa linha de pesquisa, tais trabalhos trazem propostas de ensino ou buscam enfatizar o desenvolvimento de experiências com professores e alunos de diferentes etapas da escolarização.

O primeiro trabalho de Modelagem Matemática realizado no PPGEM é considerado também o pioneiro no Brasil específico na área do ensino e da aprendizagem na Educação Básica (FIORENTINI, 1994). Trata-se do estudo de Dionísio Burak, defendido em 1987, em que o autor propõe a Modelagem Matemática como metodologia alternativa para o ensino de Matemática na Educação Básica, mais especificamente na $5^{\mathrm{a}}$ série do $1^{\circ}$ grau (atual $6^{\circ}$ ano do Ensino Fundamental - Anos Finais). Além de descrever a elaboração da proposta metodológica e sua aplicação com um grupo de professores de $1^{\circ}$ e $2^{\circ}$ graus, Burak discute em sua dissertação as perspectivas didático-pedagógicas da Modelagem, destacando, sobretudo, a motivação e o interesse que essa metodologia proporciona ao estudo da Matemática. Vale destacar que a opção de Burak pela pesquisa com Modelagem Matemática, segundo ele

\footnotetext{
${ }^{39}$ Regina Buriasco foi orientada por Ubiratan D'Ambrosio e desenvolveu o estudo "A matemática de dentro e de fora da escola: do bloqueio à transição".

${ }^{40}$ Marcelo de Carvalho Borba foi orientado por Maria A. V. Bicudo e co-orientado por Eduardo Sebastiani Ferreira. A dissertação, defendida em 1987, intitulada: "Um Estudo em Etnomatemática: sua Incorporação na Elaboração de uma Proposta Pedagógica para o Núcleo-Escola da Vila Nogueira - São Quirino", é considerada o primeiro trabalho em nível de pós-graduação voltado à Etnomatemática.

${ }^{41}$ Tomamos como referência os dados disponíveis no catálogo de resumos de dissertações do Programa de PósGraduação em Educação Matemática da Unesp - Rio Claro, 1987 - 1994 (BORBA, 1995). Consideramos somente as dissertações defendidas até 1990, dada a periodização por nós proposta para este estudo.
} 
próprio, incide do seu contato com Bassanezi, quando cursou disciplinas de cursos de verão na Unicamp, no início da década de 1980, e da sua participação como colaborador do primeiro curso de Especialização em Modelagem, ofertado na Fafig de Guarapuava, instituição da qual Burak era professor. O curso teve início em janeiro de 1983, dois meses antes de sua ida para Rio Claro, e foi determinante para a definição da temática de sua pesquisa. Foi observando as atividades desenvolvidas no curso e todo o movimento em torno da Modelagem Matemática que ele se decidiu pelo tema de pesquisa e, principalmente, por ter o ensino de $1^{\circ}$ grau como foco.

O envolvimento com os cursos de especialização foi também o que motivou Marineusa Gazzetta a estudar Modelagem Matemática no Mestrado em Rio Claro. Sua pesquisa, defendida em 1989, foi a segunda a abordar o tema. Marineusa integrou a equipe itinerante do IMECC na realização dos cursos de especialização com ênfase na Modelagem, sendo docente em diversas edições desses cursos, em distintas instituições brasileiras.

Em sua dissertação, ela faz um relato e uma reflexão das experiências envolvendo a Modelagem Matemática a partir de sua trajetória acadêmica e da trajetória do grupo do IMECC, ao longo de aproximadamente sete anos, dando destaque ao seu envolvimento com os cursos de especialização. Ela afirma em seu trabalho que a possibilidade de participar do grupo do IMECC constituído por professores-pesquisadores comprometidos com a Educação levou-a a repensar o 'ser' da Educação e a vislumbrar “a Modelagem como estratégia para a aprendizagem da Matemática, numa concepção que visa à pessoa do estudante" (GAZZETTA, 1989, p. 2).

No mesmo ano de conclusão da dissertação de Gazzetta, em 1989, Maria Dolis também defendeu seu trabalho no PPGEM, o primeiro a tratar da Modelagem Matemática no ensino de $3^{\circ}$ grau. Nesse estudo, a autora realiza primeiramente uma revisão bibliográfica para tomar conhecimento do processo de Modelagem Matemática e, em seguida, delineia um plano de ensino de Cálculo para a área de Ciências Biológicas da Universidade Estadual de Maringá. Mostra, ainda, em seu trabalho, as possibilidades da abordagem de conceitos como Derivada, Integral, Limites e Equações Diferenciais, explorando, para tanto, um problema relativo à pesca indiscriminada, vindo de um estudo realizado anteriormente por seu orientador, Rodney Bassanezi. Dolis, no período em que desenvolveu seu mestrado, acompanhou a equipe do IMECC num dos cursos realizados em Guarapuava (1985-1986), participando ativamente das atividades como ouvinte, no intuito de melhor compreender o processo de Modelagem Matemática. 
No ano seguinte à defesa de Dolis, em 1990, duas outras dissertações sobre Modelagem Matemática são concluídas na Unesp de Rio Claro: a de Maria Queiroga Amoroso Anastácio e de Maria Salett Biembengut.

$\mathrm{Na}$ entrevista que nos concedeu, Maria Salett revela que uma das experiências, em especial a primeira que realizou com Modelagem, foi determinante para os rumos de sua carreira profissional e acadêmica. Trata-se de um projeto que desenvolveu com alunos de uma $8^{a}$ série do período noturno, de uma escola da periferia de Mogi Guaçu - a Escola da Estiva. Durante o período em que realizou o mestrado em Rio Claro, Biembengut também integrou a equipe do IMECC no desenvolvimento dos cursos de especialização, atuando primeiramente como monitora, depois como docente em algumas instituições brasileiras. Sua imersão em atividades com/pela Modelagem Matemática e seu envolvimento com pesquisadores da Educação Matemática possibilitaria que ela ampliasse seus contatos e, pouco tempo depois de finalizar sua dissertação, se tornasse secretária geral ${ }^{42}$ da Sociedade Brasileira de Educação Matemática - Sbem, cargo que exerceu de 1993 a 1995.

As discussões para a criação de uma sociedade que congregasse profissionais que atuassem com Educação Matemática - compreendida em seus mais amplos aspectos interdisciplinares, didáticos, pedagógicos, sociológicos, filosóficos, históricos e sociais tiveram início também na década de 1980, mais especificamente no ano de 1985, quando um grupo de pesquisadores - com a forte presença de Ubiratan D'Ambrosio - assumiu um compromisso, em Guadalajara, no México, durante a VI Conferência Interamericana de Educação Matemática (Ciaem), de "propor a criação da Sociedade Brasileira de Educação Matemática, com o objetivo de estimular e coordenar o intercâmbio de estudos e atividades realizadas no Brasil na área de Educação Matemática"43.

Posteriormente, em 1987, por ocasião da realização do primeiro Encontro Nacional de Educação Matemática (ENEM), na PUC-SP, foi proposta formalmente a criação da referida Sociedade e instituída uma comissão com a tarefa de pensar e produzir seus estatutos. Após aproximadamente 50 reuniões em distintas localidades do país em que se elaboraram e se discutiram os termos de tal documento, num movimento de construção coletiva e democrática do qual participaram cerca de 1200 pessoas, o estatuto foi homologado no II ENEM, na cidade de Maringá/PR, em 1988, quando, por deliberação da Plenária Final do evento, nascia oficialmente a Sociedade Brasileira de Educação Matemática (PEREIRA, 2005).

\footnotetext{
${ }^{42}$ Como era chamada, à época, a posição de Presidente.

${ }^{43}$ Excerto de uma carta selando o compromisso dos participantes brasileiros no CIAEM de fundar a sociedade, disponível em Pereira (2005).
} 


\section{Considerações finais}

Decisivamente, os movimentos iniciados na década de 1980 no IMECC em torno da Modelagem Matemática se complementaram e interpenetraram atingindo outros focos no Brasil, como o PPGEM de Rio Claro, que foi responsável por redimensionar a pesquisa da área para o campo da Educação. Um desses movimentos - os cursos de especialização iniciados em Guarapuava - em particular, atraiu alunos interessados na temática e fomentou o desenvolvimento das primeiras pesquisas em Modelagem voltadas ao ensino e à aprendizagem da Matemática, contribuindo para o surgimento de novos núcleos de pesquisa na área. Os novos pesquisadores, ao se vincularem às instituições de ensino em distintas regiões brasileiras, aderiram ou criaram linhas de investigação voltadas à Modelagem, como Dionísio Burak e Maria Salett Biembengut que, após defenderem suas dissertações, passaram a orientar trabalhos acadêmicos e, posteriormente, a coordenar grupos de pesquisa na área.

Parece não ter sido mera coincidência que a oferta do primeiro curso de Especialização em Modelagem Matemática tenha ocorrido na mesma época em que se davam as discussões para implantação do primeiro curso de Mestrado em Educação Matemática no país. Havia, na verdade, “um movimento embrionário de educadores matemáticos que vinha se desenvolvendo espontaneamente em vários estados brasileiros, sem qualquer organização ou representação coletiva" (MUNIZ, 2013). Assim, enquanto um grupo de matemáticos do IMECC, em Campinas, articulava-se em torno de uma proposta metodológica, outro grupo, composto por matemáticos e uma pedagoga, da Unesp de Rio Claro, articulava-se em torno do projeto de um curso de pós-graduação. O reconhecimento de suas ideias e práticas entre os pares viriam contribuir para a constituição de uma área emergente e para a caracterização dos conhecimentos que produziam/produzem como Educação Matemática. Esses profissionais, ao se unirem, mesmo em meio às barreiras burocráticas e políticas, encontraram força e determinação para a criação do primeiro Programa de Pós-Graduação em Educação Matemática, contribuindo, sobremaneira, para a consolidação de um campo profissional e científico que emergia no Brasil: a Educação Matemática.

\section{Referências}

ABRÃO, J. C. (2007). Trajetórias dos marcos referenciais do lato sensu: da Lei de Diretrizes e Bases da Educação de 1961 à Resolução n. ${ }^{\circ} 01$ - CNE de2001. In: REUNIÃO DA ANPED, 30, GT: Política de Educação Superior, 2007, Caxambu/MG. Anais... Caxambu, 2007, p. 01-17.

ALMEIDA, M. A. Formação do professor para a educação especial: história, legislação e competências. Cadernos de Educação Especial, Santa Maria, v. 1, n.24, p. 23-32, 2004. 
BICUDO, M. A. V. A Pós-Graduação em Educação Matemática de Rio Claro: historiando sua trajetória. In: NARDI, R.; GONÇALVES, T. V. O. (Org.). Pós-Graduação em Ensino de Ciências e Matemática no Brasil: memórias, programas, consolidação da pesquisa na área. São Paulo: Livraria da Física, 2014. p. 85-97.

BIEMBENGUT, M. S. 30 Anos de Modelagem Matemática na Educação Brasileira: das propostas primeiras às propostas atuais. Alexandria: Revista de Educação em Ciência e Tecnologia, Florianópolis, v. 2, n. 2, p.7-32, 2009.

BIEMBENGUT, M. S. ICTMA: Ideias da História. In: CONFERÊNCIA INTERAMERICANA DE EDUCAÇÃO MATEMÁTICA - CIAEM, 14, 2015, Tuxtla Gutiérrez. Anais...Tuskla Gutierrez: 2015.

BOLDRIN, L. C. F. A especialização como espaço de formação continuada do professor de Educação Infantil em Goiás. 2007. Tese (Doutorado em Educação) - Faculdade de Educação, Universidade Federal de Goiás, Goiânia, 2007.

BORBA, M. de C. Catálogo de resumos de dissertações do Programa de Pós-Graduação em Educação Matemática da UNESP - Rio Claro, 1987 - 1994. Rio Claro: UNESP, 1995.

BRASIL. Presidência da República. Lei no 4.024, de 20 de dezembro de 1961. Fixa as Diretrizes e Bases da Educação Nacional. Brasília, 1961. Disponível em:

http://www.planalto.gov.br/ccivil_03/leis/L4024.htm. Acesso em: 25 jul. 2018.

BRASIL. Conselho Federal de Educação. Parecer nº 977/1965. Estabelece o sistema de pósgraduação brasileiro. Brasília, 1965. Disponível em:

https://capes.gov.br/images/stories/download/avaliacao/avaliacao-n/Parecer-977-1965.pdf. Acesso em: 20 jul. 2018.

BRASIL. Ministério de Educação e Cultura. Reforma universitária: relatório do grupo de trabalho criado pelo decreto n. 62.937/68. Brasília: Presidência da República, 1968.

BRASIL. Conselho Federal de Educação. Resolução no 14, de 23 de novembro de 1977.

Regulamenta a validade dos Cursos de Aperfeiçoamento e Especialização como instrumento de qualificação na carreira de Magistério Superior. Brasília, DF, 1977. Disponível em:

http://www.consultaesic.cgu.gov.br/busca/dados/Lists/Pedido/Attachments/411652/RESPOSTA_PED IDO_Res.pdf . Acesso em: 02 set. 2017.

BRASIL. Conselho Federal de Educação. Resolução no 12, de 6 de outubro de 1983. Fixa condições de validade dos certificados de cursos de aperfeiçoamento e especialização para o Magistério Superior, no sistema federal. Brasília, DF, 1983. Disponível em:

http://www.consultaesic.cgu.gov.br/busca/dados/Lists/Pedido/Attachments/433200/RESPOSTA_PED IDO_Res.pdf. Acesso em: 02 mai. 2018.

CARVALHO, H. M Modelagem Matemática: elementos históricos sobre seu desenvolvimento em cursos de pós-graduação. 2010. Dissertação (Mestrado Profissional em Matemática Universitária) Instituto de Geociências e Ciências Exatas, Universidade Estadual Paulista, Rio Claro.

D’AMBROSIO, U. Uma síntese do Programa Experimental de Mestrado em Ensino de Ciências e Matemática da UNICAMP/OEA/MEC (1975 a 1984). In: NARDI, R.; GONÇALVES, T. V. O. (org.). Pós-Graduação em Ensino de Ciências e Matemática no Brasil: memórias, programas, consolidação da pesquisa na área. São Paulo: Livraria da Física, 2014, p. 56-84.

FILLOS, L. M. Modelagem Matemática nos anos 1980: narrativas e itinerários de cursos de especialização. 2019. Tese (Doutorado em Educação Matemática), 2019. 
FIORENTINI, D. Rumos da pesquisa brasileira em educação matemática: o caso da produção científica em curso de pós-graduação. 1994. Tese (Doutorado em Educação: Metodologia de Ensino) Faculdade de Educação, Universidade Estadual de Campinas, Campinas, 1994.

FIORENTINI, D. Estudo de algumas tentativas pioneiras de pesquisa sobre o uso da Modelagem Matemática no ensino. In: INTERNATIONAL CONGRESS ON MATHEMATICAL EDUCATION ICME, 8, 1996, Sevilha. Anais... Sevilha: ICME, 1996, p. 1-15.

FIORENTINI, D. LORENZATO, S. Investigação em Educação Matemática: percursos teóricos e metodológicos. Coleção formação de professores. Campinas: Autores Associados, 2006.

FONSECA, D. M. O pensamento privatista em educação. Campinas: Papirus, 1992.

FONSECA, D. M. Contribuições ao debate da pós-graduação lato sensu. Revista Brasileira de PósGraduação, Brasília, v. 1, n. 2, p. 173-182, 2004.

FAFIG - FUNDAÇÃO FACULDADE DE FILOSOFIA, CIÊNCIAS E LETRAS DE GUARAPUAVA. Regimento dos Cursos de Especialização. Disponível no Arquivo da Pró-Reitoria de Pesquisa da Unicentro, 1981.

GARNICA, A. V. M.; BICUDO, M. A. V. Uma sessão de Memória: entrevista com Maria Aparecida Viggiani Bicudo. In: DASSIE, B.A.; COSTA, D. A. da. (Org.). História da Educação Matemática e formação de professores. São Paulo: Editora Livraria da Física, 2018. p. 187-241.

GAZZETTA, M.; D'AMBROSIO, U.; MACHADO, C. R. R.; AIDAR, E. M.; ZUTIN, M. C. G.; PRADO, M B. B.; MASTINE, R. L. B. Iniciação à Matemática. v. 3. Campinas: Editora da Unicamp, 1986.

GAZZETTA, M. A Modelagem como estratégia de aprendizagem da matemática em cursos de aperfeiçoamento de professores. 1989. Dissertação (Mestrado em Educação Matemática) - Instituto de Geociências e Ciências Exatas, Universidade Estadual Paulista, Rio Claro, 1989.

MARAFON, M. R. C. Articulação pós-graduação e graduação: desafio para a educação superior. 2001. Tese (Doutorado em Educação) - Faculdade de Educação, Universidade Estadual de Campinas, Campinas, 2001.

MARCONDES, G. G. et al. FAFIG: 15 anos de história. Guarapuava: FAFIG, 1985.

MARTINS-SALANDIM, M. E. A interiorização dos cursos de Matemática no Estado de São Paulo: um exame da década de 1960. 2012. Tese (Doutorado em Educação Matemática). Instituto de Geociências e Ciências Exatas, Universidade Estadual Paulista, Rio Claro, 2012.

MORAIS, M. B. Se um viajante... Percursos e histórias sobre a formação de professores de matemática no Rio Grande do Norte. 2017. Tese (Doutorado em Educação Matemática). Instituto de Geociências e Ciências Exatas, Universidade Estadual Paulista, Rio Claro, 2017.

MUNIZ, N. C. Relatos de Memórias: a trajetória histórica de 25 anos da Sociedade Brasileira de Educação Matemática (1988-2013). São Paulo: Livraria da Física, 2013.

OLIVEIRA. A. D. S. Os cursos de pós-graduação lato sensu em Educação Infantil na Bahia: políticas e prática da universidade pública. 2012. Tese (Doutorado em Educação) - Faculdade de Educação, Universidade Federal de Goiás, Goiânia, 2012. 
PEREIRA, D. J. R. História do movimento democrático que criou a Sociedade Brasileira de Educação Matemática - SBEM. 2005. Tese (Doutorado em Educação) - Faculdade de Educação, Universidade Estadual de Campinas, Campinas, 2005.

SHEEN, M. R. C. C. Política educacional e hegemonia: a criação das primeiras universidades estaduais no Paraná da década de 1960. 2000. Tese (Doutorado em Educação) - Faculdade de Educação, Universidade Estadual de Campinas, Campinas, 2000.

SOUZA, G. L. D. Três décadas de Educação Matemática: um estudo de caso na Baixada Santista no período de 1953 a 1980. 1998. Dissertação (Mestrado em Educação Matemática) - Instituto de Geociências e Ciências Exatas, Universidade Estadual Paulista, Rio Claro, 1998.

VIANNA, C. R. Vidas e circunstâncias na Educação Matemática. 2000. Tese (Doutorado em Educação) - Faculdade de Educação, Universidade de São Paulo, São Paulo, 2000.

WACHOWICZ, R. C. Universidade do Mate: História da UFPR. 2.ed. Curitiba: Editora UFPR, 2006. 